\title{
Evaluation of Computer-Based Learning Materials in Agricultural Information Dissemination in Sri Lanka
}

\author{
U.I. Dissanayeke, H.V.A. Wickramasuriya and R. Wijekoon ${ }^{1}$ \\ Postgraduate Institute of Agriculture \\ University of Peradeniya \\ Peradeniya, Sri Lanka
}

\begin{abstract}
Cyber extension, in which computer technology is used to disseminate agricultural information was initiated in 2004 in Sri Lanka with a set of agriculture related Computer-Based Learning Materials (CBLMs) produced and distributed among 45 Cyber Extension Units (CEUs) in the country. However, formal research carried out to test these CBLMs at the field level was very limited. Hence, the objectives of the study were to (i) identify the present status of using CBLMs in agricultural extension in Sri Lanka, and (ii) to evaluate CBLMs used in agricultural extension. Thirteen CEUs were selected using stratified random sampling. Extension officers $(n=40)$ and farmers $(n=70)$, who were exposed to CBLMs were interviewed using two pre-tested interview schedules, to evaluate the content, user-interface, motivation, and media use of CBLMs. Data analysis was done using descriptive statistics and mean comparisons.
\end{abstract}

Officers were found to be using CBLMs for both receiving and disseminating agricultural information, whilst farmers mainly used them for receiving such information. Use of CBLMs by the officers was positively related to their education $(r=0.457, p=0.003)$ and computer experience ( $r=0.418, p=0.007)$. The majority (76.1\%) of the high users were Agricultural Instructors $(p=0.000)$. Use of CBLMs by farmers too was positively related to their education $(r=0.319 p=0.046)$. Out of those who had been exposed to cyber extension, the majority of farmers (96.9\%) and officers (80\%) rated CBLMs as highly effective in terms of delivering agricultural information. Farmers rated CBLMs ahead of officers ( $t=3.01$, $p=0.003)$. The CBLMs presently used at CEUs are effective in terms of delivering agricultural information. It is important to provide computer training to extension officers attached to the CEUs.

\section{INTRODUCTION}

Agriculture is very important for the socio-economic development of the rural community, as a source of income as well as a way of living. Agricultural extension plays a key role in agricultural development by providing the necessary information, related to the latest innovations, to the farming community, thus bridging the gap between research and practice. However, the traditional methods of information dissemination have become less successful and less cost effective due to various reasons. The average number of farm families to be served by a single Agriculture Instructor (AI) has exceeded 4000, which is an extremely hard target to achieve. The withdrawing of grass root extension workers from extension activities and the overburdening of the remaining extension workers with other duties are some of the other constraints (CARP, 2003). To strengthen the linkages between extension, research, marketing networks and farmers, a Cyber Agricultural Extension Mechanism was initiated in

${ }^{1}$ Audio Visual Centre, Department of Agriculture, Peradeniya, Sri Lanka 
2004 to deliver agricultural information to end users in an affordable and appealing manner (Wijekoon et al., 2008). Under this project a set of agriculture related Interactive Multimedia Compact Discs (IMMCDs) were produced. Multimedia learning material is broadly referred to as digital learning resources that combine text, images, and other media and that are intended for re-use across educational settings (Hamel and Ryan Jones, 2002). These IMMCDs were distributed among 45 Cyber Extension Units (CEUs) in different parts of the island, housed in Agrarian Service Centres (ASCs), so that farmers would have free access to cultivation related information. These centres will act as local information resource centers, with computers carrying expert systems to help farmers to make decisions. According to Sharma (2009), India has sucesfully utilized ICT in agricultural extension. They have established information kiosks at village level which provides details on various agricultural practices along with market information, and other related information such as weather forecasts.

However, not much research was carried out to evaluate these Computer-Based Learning Materials (CBLMs) at the field level. The extent of use of these CBLMs by the target audience in obtaining and disseminating agricultural information, and the effectiveness of those in terms of the e-extension strategy is yet to be investigated.

The effectiveness of CBLMs was evaluated from the end users' perspective (Hillman, 1998), mainly because it provides the actual effectiveness in terms of reaching the expected users, delivering information and ultimately achieving the expected objectives.

Thus the objectives of this study were, (i) to identify the present status of using CBLMs in disseminating agricultural information, (ii) to evaluate CBLMs used in agricultural extension, and (iii) to provide recommendations to improve the usage of CBLM in agricultural information dissemination in Sri Lanka. The scope of the study was limited to evaluate the following: IMMCDs, Video CDs and PowerPoint Presentations used in the CEUs in farmer training.

\section{METHODOLOGY}

Thirteen CEUs, out of the 45, were selected for the study using stratified random sampling. The selected CEUs belonged to nine districts namely Anuradhapura, Polonnaruwa, Gampaha, Kandy, Kegalle, Kurunegala, Badulla, NuwaraEliya and Matale. Forty Extension officers $(n=40)$ from those who had used IMMCDs in farmer training were selected randomly from the selected CEUs. This group consisted of Agricultural Research and Production Assistants (ARPAs), Agricultural Instructors (AIs) and Officers in charge of CEUs. The latter two groups were not mutually exclusive. Seventy farmers, from those who had been exposed to CBLMs during the previous six months, were also interviewed. Both groups were interviewed using two pre-tested interview schedules.

Questions were formulated to evaluate CBLMs using four major indicators, namely content, motivation (Leacock and Nesbit, 2007), user interface (Cho et al., 2009), and media usage (Gopalam et al., 2004). The level of use of CBLMs by the extension officers was determined using 4 indicators, namely number of IMMCDs watched, number of farmer trainings conducted using IMMCDs, number of training support materials produced using IMMCDs, and level of use of IMMCDs to receive agricultural information. The reliability co-efficient alpha value for the scale was 0.8273 . 
Descriptive statistical tests, namely frequency analysis and cross tabulations were used to explain the variables. Chi-square analysis and Pearson product-moment correlation analysis was used to test relationships between variables. Relationships were considered as significant when the probability value was less than 0.05 . Mean comparisons for the two groups, farmers and officers, were done using independent sample t-tests.

\section{RESULTS AND DISCUSSION}

\section{Use of CBLMs by officers and farmers}

Officers were found to be using CBLMs both for obtaining and disseminating agricultural information, while farmers mainly used them for obtaining information. The number of IMMCDs viewed by a farmer seems to be fairly low compared to an officer. The average number of IMMCDs watched by an officer was 14 whereas for farmers it was only 2 . Even though the majority $(61.3 \%)$ of farmers have viewed only one or two CDs, many $(45 \%)$ of them had watched the same IMMCD several times as they had found the information useful. The maximum number of CDs watched by a farmer was 10 , while only $2.6 \%$ of the farmers had watched more than eight CDs. On the other hand nearly $46 \%$ of the officers had watched more than $10 \mathrm{CDs}$. The average number of farmer trainings conducted by an officer was found to be 31 .

Farmers' low exposure to IMMCDs in general, and also when compared to officers, was mainly due to the less availability of IMMCDs for different agricultural practices. The majority $(56 \%)$ of farmers were engaged in a maximum of 2 agricultural activities during the last three seasons. Further $92 \%$ of the farmers were involved in maximum of up to 5 agriculture activities. Consequently, the number of CBLMs watched by an individual farmer was less, as many of them usually used only the CBLMs that were relevant to their current cultivation. It was also seen that in a particular CEU, a few CDs were being frequently used for most of the farmer training classes. These were the crops most commonly grown in that area.

Secondly, due to their poor computer skills, farmers had to rely heavily on the assistance of the Officers In-charge of the CEUs in order to use CBLMs. Considering the fact that most AIs are available in the Agrarian Service Centres only on one working day per week, and also due to the other duties they have to perform, it is apparent that officers cannot invest much of their time in helping farmers to go through CBLMs. Due to these reasons it was observed that most farmers (82\%) had watched IMMCDs only during farmer training programmes.

\section{Factors affecting the use of CBLMs}

The level of use of CBLMs by the officers was positively influenced by their education $(\mathrm{r}=$ $0.457 \mathrm{p}=0.001)$ and computer experience $(\mathrm{r}=0.418 \mathrm{p}=0.001)$ (Table 1). Furthermore, educated farmers too were found to be using CBLMs more than the less educated $(\mathrm{r}=0.319$ $\mathrm{p}=0.046$ ). These findings are similar to Alvarez and Nuthall (2006) who reported a positive relationship between education and use of computer-based information systems in agriculture information management.

Table 1. Correlation between using CBLMs and personal attributes of officers 


\begin{tabular}{lcc}
\hline Variable & $\mathrm{R}$ & $\mathrm{P}$ \\
\hline Computer experience & 0.418 & 0.007 \\
Education & 0.457 & 0.003 \\
\hline
\end{tabular}

The level of use of CBLMs had no relationship with the age or sex of the respondents according to the Chi-square tests conducted. According to the findings, the majority $(76.1 \%)$ of the high users were the AIs, while most $(84.2 \%)$ of the low users were ARPAs $\left(\chi^{2}=\right.$ 14.593, $\mathrm{p}=0.000)$ (Table 2).

Similarly, Smith et al., (2004) also found that farmers' exposure to computer technology is ultimately more important in adopting the use of computers or internet, than their age or farm size.

Table 2. Use of CBLMs and employment category

\begin{tabular}{lcccc}
\hline Job category & \multicolumn{4}{c}{ Use of CBLMs } \\
\cline { 2 - 5 } & \multicolumn{3}{c}{ Low } & \multicolumn{3}{c}{ High } \\
\cline { 2 - 5 } & No & $\%$ & No & $\%$ \\
\hline ARPA & 16 & 84.2 & 5 & 23.9 \\
AI and other & 3 & 15.8 & 16 & 76.1 \\
\hline Total & 19 & 100 & 21 & 100 \\
\hline & & $\boldsymbol{\chi}^{\mathbf{2}}=\mathbf{1 4 . 5 9 3}, \mathbf{p}=\mathbf{0 . 0 0 0}$ &
\end{tabular}

The AIs and Officers in-charge of CEUs were officially assigned to use IMMCD in farmer training programmes. They were also given computer training at the beginning and throughout the CEU establishment process, while frequent evaluations were carried out to test their performances by the DOA. Factors such as the number of farmer training programmes conducted using IMMCDs, and number of teaching aids produced using IMMCDs, were generally monitored during these evaluations. Since AIs and Officers in charge of CEUs were mainly responsible to manage the CEU, they needed to perform better in these aspects. However, ARPAs were not bound to do so. They are allowed to use the $\mathrm{CEU}$ to watch $\mathrm{CDs}$, and to produce training aids based mainly on their interest.

\section{Evaluating CBLMs}

According to the findings, farmers have assigned higher effectiveness scores for CBLMs when compared to the officers. An independent sample t-test showed that the difference was significant $(t=3.01, p=0.003)$. Interestingly, none of the officers or farmers rated CBLMs as poor in the overall evaluation (Table 3 ).

Table 3. Evaluation of CBLMs by officers and farmers

\begin{tabular}{|c|c|c|}
\hline Overall mean score & Officers $(n=40)$ & Farmers $(n=65)$ \\
\hline Good $(3.6-5.0)$ & 80 & 96.9 \\
\hline Average $(2.6-3.5)$ & 20 & 3.07 \\
\hline \multirow[t]{2}{*}{ Poor $(1-2.5)$} & 0 & 0 \\
\hline & Mean 4.022 & Mean 4.284 \\
\hline
\end{tabular}


When compared to officers, farmers have assigned significantly higher effectiveness scores for two indicators, namely content $(\mathrm{t}=3.574, \mathrm{p}=0.001)$ and media usage $(\mathrm{t}=3.674, \mathrm{p}=$ 0.000 ). This difference is most probably due to the different expectations of farmers and officers in terms of the usage of CBLMs. Farmers are mainly expected to use IMMCDs to receive technical information related to agriculture. Since farmers are supposed to use CBLMs only as passive recipients, as long as the information presented in CDs are adequate and understandable, farmers see them as useful. On the other hand, officers are supposed to use CDs both in receiving and disseminating agricultural information. They are further instructed to produce training support materials, and use them in farmer training classes. Thus, the officers are expected to use the CBLMs in a more advanced way, including the dissemination of agricultural information. With these demanding tasks, officers could find the information in CDs as not adequately sufficient to meet their needs compared to farmers.

Officers' familiarity with the technical information presented in IMMCDs could be another possible reason for the lower rating. Since they are more used to reading technical agricultural publications such as bulletins and pamphlets, they would find that the materials presented in CDs are not novel to them. Farmers did not have access to all this printed material as stated by them during the discussions. Even if they did, they would find the same content as more exciting and fresh. Thus, farmers will probably be more satisfied with the CBLMs in comparison to the officers.

The effectiveness scores given for the user-interface of CBLMs, were quite different to the above findings. The officers gave significantly higher effectiveness scores than farmers $(t=$ $2.05, \mathrm{p}=0.04)$. This was most probably due to their familiarity with navigation aspects as they were frequently using CBLMs, whereas the farmers had difficulty in navigating through the material due to their less experience in using computer-based materials.

Although both the respondents evaluated CBLMs as 'good', giving fairly high effectiveness scores, when they were asked to rank CBLMs against four other sources of information, both groups preferred to deliver and/or obtain agricultural information through the extension officers attached to ASCs in comparison to CBLMs. However, farmers rated CBLMs as the second most effective source to receive information, whereas officers rated CBLMs in the fourth place, i.e., after both the mass media, and the publications of Department of Agriculture. This is most probably due to fact that, the officers are referring to the majority of the general farming community who are not aware of cyber extension. Since cyber extension is still at its early phase of development, many officers would not consider it as an effective method to reach the majority of the farmers.

\section{Suggestions to improve CBLMs}

Both farmers and officers provided many suggestions to improve the use of CBLMs in agricultural information dissemination. For example, they suggested to include more photographs, and video clips, especially related to pest and disease management. A few officers (20\%) and farmers (13.3\%), suggested increasing the size of video clips so that they can better use the CBLMs during farmer training classes as CEUs do not have multimedia projectors. It was observed that certain CEUs did not have adequate space to conduct small group farmer training. Thus some officers suggested that cyber units should be provided with better facilities to conduct farmer training programmes for groups of farmers. Officers comment that even when they prepare PowerPoint presentations, they still have to show it using the computer monitor and thus, this is not practicable for groups of farmers. 
About $18 \%$ of the officers expressed their concern on the content of IMMCDs, suggesting that the content of the CDs should be simpler and understandable for farmers. They commented that farmers cannot understand some of the technical terms used in the CDs. Some of the respondents (7.5\%) suggested including more practical details than scientific information. However, none of the farmers seems to have problems related to the content of IMMCDs.

Both officers (18\%) and farmers $(17.3 \%)$ requested to include more information related to certain crop management practices such as pesticide recommendations, marketing facilities, and the latest technologies.

The importance of including background narration was emphasized by $20 \%$ of the farmers and $15.3 \%$ of the officers. Even though most of the farmers agreed that the text material was clear and legible, many of them prefered video clips more than text material considering the easiness in following the content.

\section{CONCLUSIONS AND RECOMMENDATIONS}

Based on the findings of this study, the following conclusions are made. Both the farmers and officers used CBLMs in obtaining agricultural information, while the latter used it in farmer training as well. Use of CBLMs by the officers was positively influenced by their computer experience and education level. The level of use of CBLMs was higher among AIs when compared to ARPAs.

The average number of IMMCDs watched by an officer was around 14, while on average farmer had watched only 2 such CDs. The average number of farmer trainings conducted by an officer was found to be 31 . Both of the above indicators were influenced mainly by their education level, computer experience and the job category. Producing training support material was somewhat limited among the officers compared to other uses. Many of the officers were using the IMMCD, and/or VCDs, directly as a training support material to show selected sections during the farmer training.

Many farmers (45\%) had watched the same video CD or IMMCD several times as they find it useful and interesting. Educated farmers preferred IMMCDs than less educated, while age and sex of the respondents did not relate to use of CBLMs in either user-group.

The majority of the users agreed that the CBLMs used for agricultural information dissemination at the CEUs were effective in terms of their content, user interface, media usage, and motivation. Farmers were highly satisfied with the content and media usage of CBLMs, and rated those two aspects significantly ahead of officers.

Both farmers and officers suggested Extension Officers as the most suitable source to deliver agricultural information to the end-users. According to the farmers surveyed, the second most effective source to deliver such information was the CBLMs.

Since computer experience is positively related to the use of CBLMs, it is recommended to provide regular computer training for extension officers so that they will be able to develop and use CBLMs in farmer training. 


\section{REFERENCES}

Alvarez, J. and Nuthall, P. (2006). Adoption of computer-based information systems: the case of dairy farmers in Canterbury, NZ, Florida, and Uruguay. Computers and Electronics in Agric. 50(1): 48-60

CARP (2003). - National Agricultural Research Policy, Sri Lanka Council for Agriculture Research Policy Ministry of Agriculture and Livestock, Colombo, Sri Lanka.

Cho, T.C.V,. Cheng, E. and Lai, W.M.J. (2009). The role of perceived user-interface design in continued usage intention of self-paced e-learning tools. Computers and Edu. 53(2):216227

Gopalam, A., Sastry, R.K., Reddy, P.V.R.M. and Madhavi, T. (2004). Multimedia in Agriculture. National Academy of Agricultural Research Management. Hyderabad, India.

Hamel, C.J. and Ryan-Jones, D. (2002). Designing instruction with learning objects [online]. International Journal of Educational Technology, 3(1) [cited 20.11.2008]. Available at: $<$ http://www.ed.uiuc.edu/ijet/v3n1/hamel/index.html $>$

Hillman, D. (1998). Multimedia Technology and Applications. Delma Publishers, USA.

Leacock, T.L. and Nesbit, J.C. (2007). A framework for evaluating the quality of multimedia learning resources. Educational Technol. and Soc. 10(2): 44-59.

Sharma, V.P. (2009). Cyber extension: Connecting farmers' in India - Some experience. [online]. [cited 12.08.2009]. Available at: http://www.gisdevelopment.net/proceedings/ mapasia/2003/papers/i4d/i4d003.htm

Smith, A.D., Paul M., Morrison, C.J.J., Goe, W.R. and Kenney, M. (2004). Computer and internet use by Great Plains farmers. [online]. UC Davis Agricultural and Resource Economics Working Paper No. 04-010. [cited 20.01.2009]. Available at Social Science Research Network: http://ssrn.com/abstract=711262

Wijekoon, R., Emitiyagoda, S., Rizwan, M.F.M., Rathnayaka, R.M.M.S. and Rajapaksha, H.G.A. (2008). Cyber extension: An information and communication technology initiative for agriculture and rural development in Sri Lanka.[online-cited 05.11.2008] Available at:http://www.fao.org/fileadmin/user_upload/kce/Doc_for_Technical_Consult/Sri_Lanka_Cy ber_Extension.pdf 